\title{
Survey of Correlation between Ethical Climate and Organizational Commitment from the Viewpoints of Operating Room and Anesthesia Technologists in Hospitals Affiliated to Iran University of Medical Sciences
}

\author{
Hannani. S1 \\ Khachian. $A^{2}$ \\ *Teymoori. $E^{3}$ \\ Haghani. $\mathrm{H}^{4}$ \\ 1- MSc in Medical-Surgical \\ Nursing, Operating Room \\ Department, Faculty of \\ Allied Medical Sciences, Iran \\ University of Medical Sciences, \\ Tehran, Iran. \\ 2- Ph.D., Nursing, Medical Surgical \\ Nursing Department, Faculty \\ of Nursing and Midwifery, Iran \\ University of Medical Sciences, \\ Tehran, Iran. \\ 3- ( ${ }^{*}$ Corresponding Author) \\ MSc of Operating Room \\ Student, Faculty of Allied \\ Medicine, Iran University of \\ Medical Sciences, Tehran, Iran. \\ Email: Teymoori.e@tak.iums.ac.ir \\ 4- MSc in Biostatistics, Instructor, \\ Faculty of Biostatistics, Iran \\ University of Medical Sciences, \\ Tehran, Iran.
}

\begin{abstract}
Introduction: Ethical climate determines how to make decisions in the organization based on ethical criteria leading to employee's satisfaction and quality of service. In a stressful environment of an operating room, the survey of the ethical climate can help to promote surgery properly. Furthermore, organizational commitment is one of the factors which determines the criteria for ethical decision making

Objective: This study aimed to determine the correlation between ethical climate and organizational commitment from the viewpoints of operating room technologists and anesthesia technologists in hospitals affiliated to Iran University of Medical Sciences.
\end{abstract}

Material and Methods: This descriptive-analytical cross-sectional study was performed on 161 operating room and anesthesia technologists working in the training hospitals of Iran University of Medical Sciences in 2019 by survey sampling. Data were collected using a questionnaire. The material consisted of three parts including demographic information, the ethical climate of Victor and his colleague, and the organizational commitment of Allen and his colleague. To analyse the data, descriptive and analytical statistics including Mean and Pearson's correlation test were used (SPSS 20) the significance level was considered less than 0.05.

Results: The mean age of the subjects was 33.02 \pm 7.18 years, ranging from 23 to 53 years old; $71.4 \%$ were females; $24.3 \%$ had undergraduate education and the rest were college students. The working experience of subjects was at most in the range of 1 to 5 years $(41.6 \%)$. The most frequent field of specialization was general surgery $(21.1 \%)$. The strongest ethical climate and organizational commitment were associated with "professionalism" and "continued commitment", respectively. The result of Pearson's test showed that there is a positive and significant relationship between ethical climate and organizational commitment. $(\mathrm{P}=0.002$ and $\mathrm{R}=0.237)$. Moreover, a significant relationship was found between its dimensions $(\mathrm{P}<0.05)$

Discussion and Conclusion: The results of present study help hospital managers to identify the ethical climate and organizational commitment, administer curricula to institutionalize ethics, and ultimately enhance organizational commitment and sustain human capital.

Keywords: Ethical Climate, Operating Room, Organizational Commitment.

Hannani S, Khachian A, Teymoori E, Haghani H. Survey of Correlation between Ethical Climate and Organizational Commitment from the Viewpoints of Operating Room and Anesthesia Technologists in Hospitals Affiliated to Iran University of Medical Sciences. Military Caring Sciences. 2020; 7 (3). 243-251. 


\title{
بررسى ارتباط جوّ اخلاقى با تعهد سازمانى از ديدكاه تكنولوزيستهاى اتاق عمل و هوشبرى بيمار ستانهاى آموزشى درمانى دانشكاه علوم يزشكى ايران
}

\author{
صديقه حنانى'، آليس خاجيان"، "*سماعيل تيمورى"، حميد حقانى"
}

جكيده

مقدمه: جوّ اخلاقى تعيين كننده تصميمَيرى در سازمان بر اساس معيارهاى اخلاقى است كه مىتواند منجر به رضايت

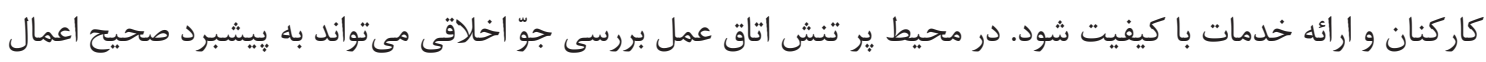

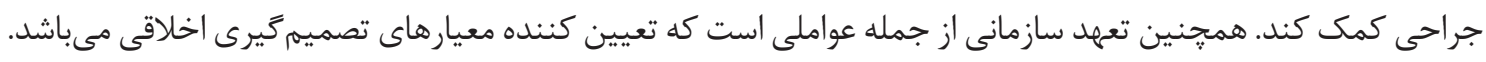

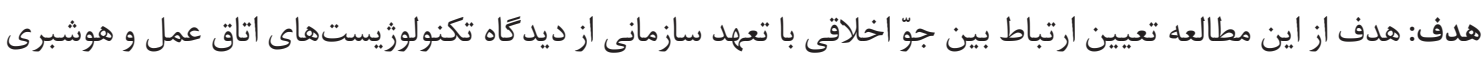

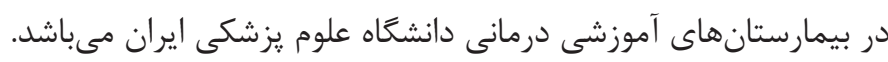

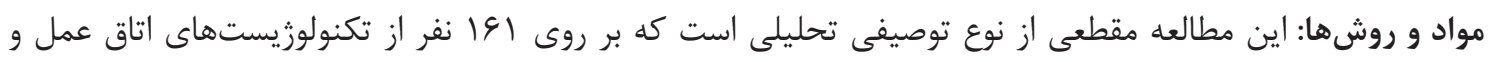

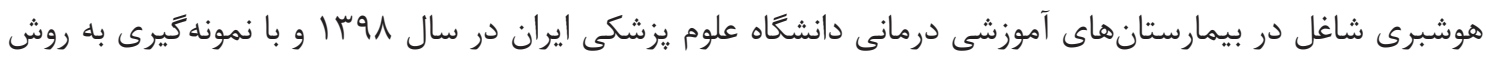

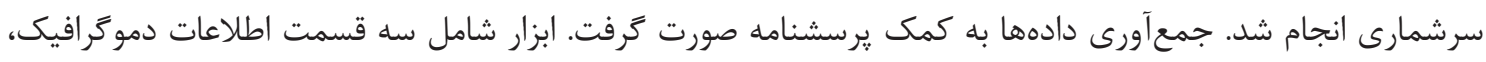

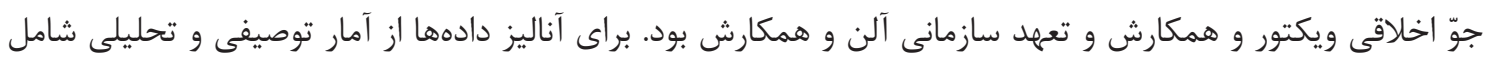

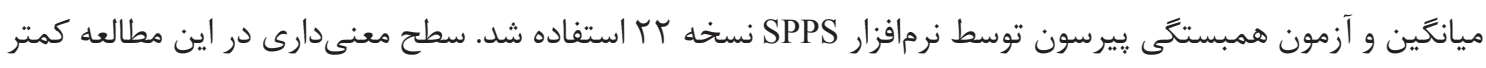

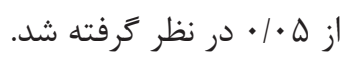

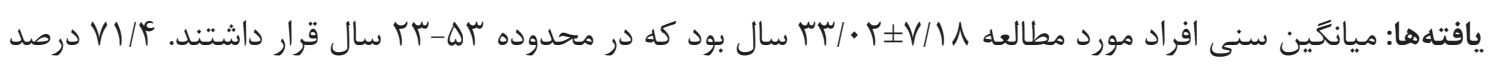

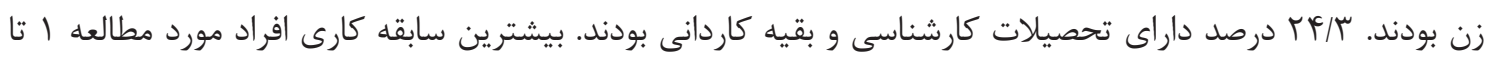

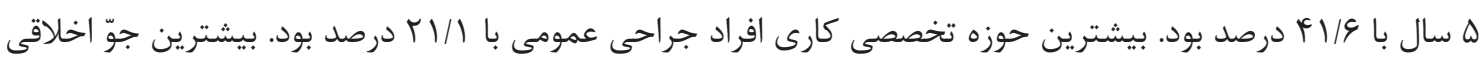

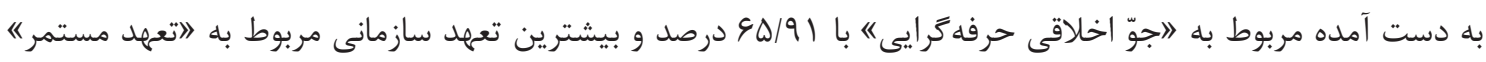

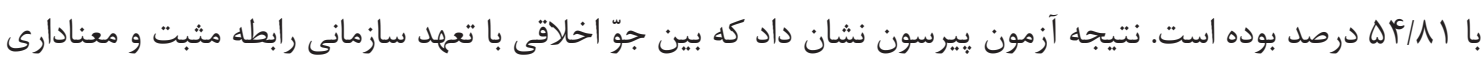

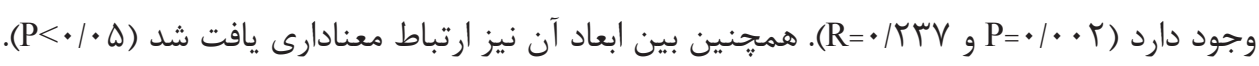

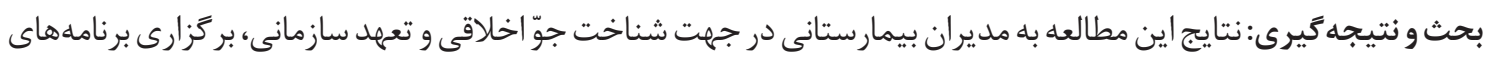

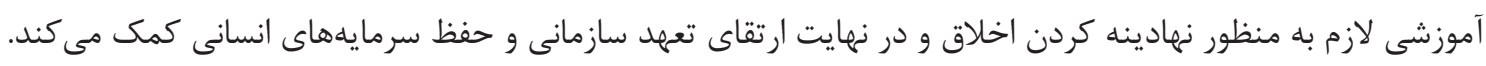
كلمات كليدى: اتاق عمل، تعهد سازمانى، جوّ اخلاقى.

تاريخ دريافت:

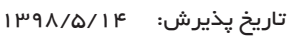

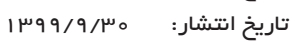


از اين رو آلن (Allen) و همكارش تعهد سازمانى را با سه بُعد تعهد عاطفى، مستمر و هنجارى مشخص كردهاند. در تعهد عاطفى إنى

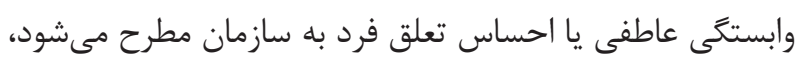

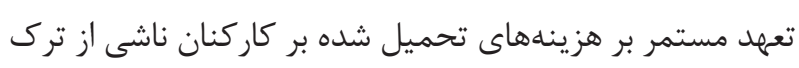

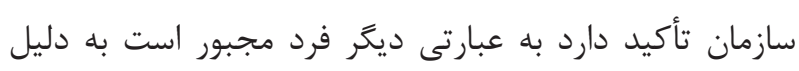

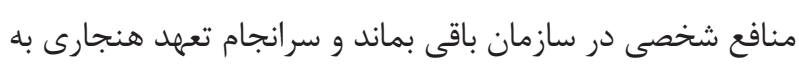

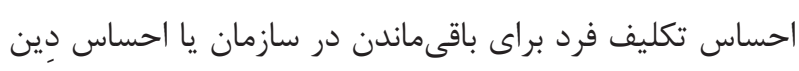
فرد در برابر سرمايهَّارى هاى انجام شده بر وى اشاره بـ دارد ( • (1).

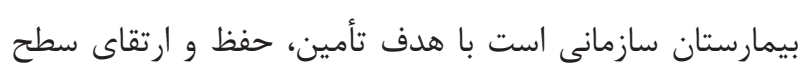

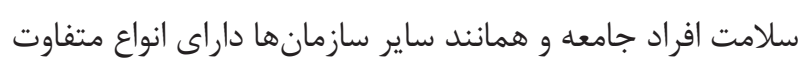
جوها، از جمله جوّ اخلاقى مىباشد (r). جوّ اخلاقى بيمارستانها

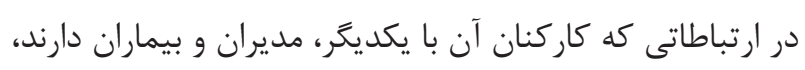

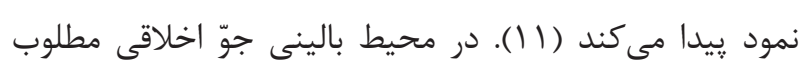
باعث تسهيل در تصميم گيرىهاى اخلاقى مى كردد كه ارتقاء آن

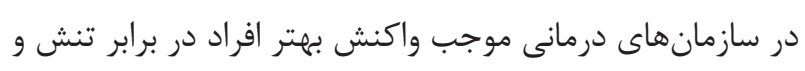
ديغر علل ايجادكننده نارضايتى در محيط كارى مى شود ( (1).

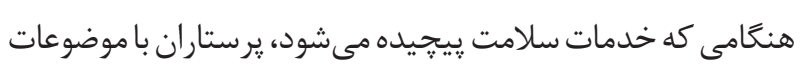

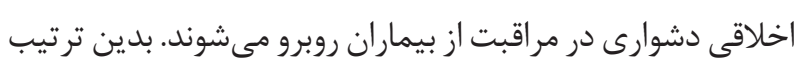

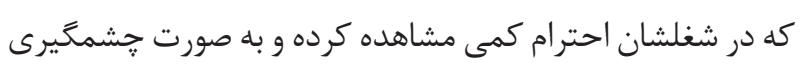

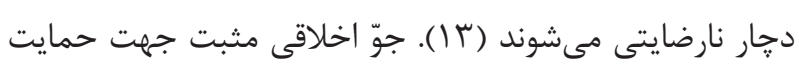

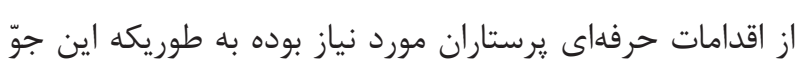
باعث تسهيل بحث و كفتكو در محيط كارى و حل مسائل بيمار

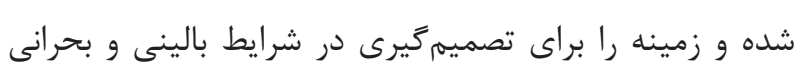

فراهم مى كند (11).

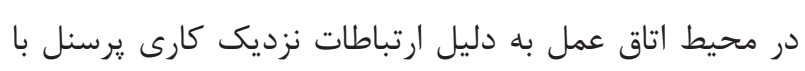

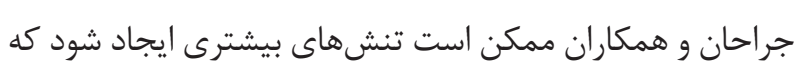

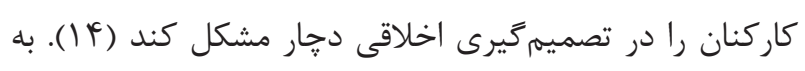

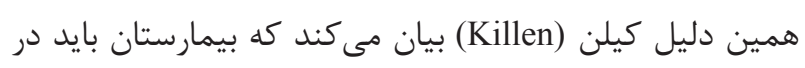
شناخت و حل مسائل اخلاقى از كاركنان اتاق عمل حمايت كند.

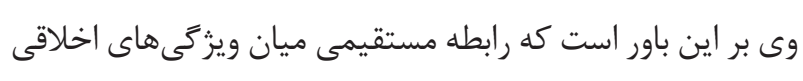

يرسنل اتاق عمل و عملكرد آنها وجود دارد (ها ().

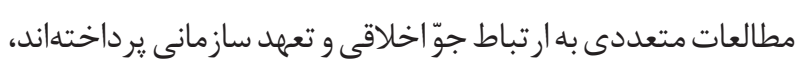

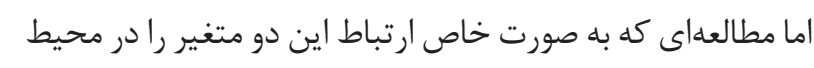

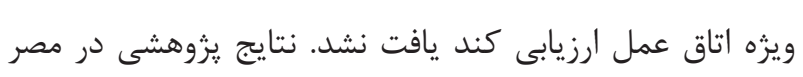

رفتارهاى اخلاقى و غير اخلاقى كار كنان بوده و تأثير مثبت يا منفى

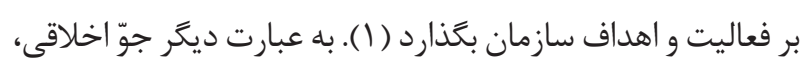

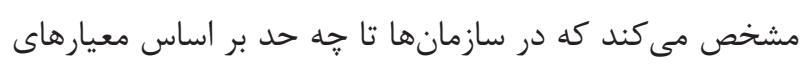

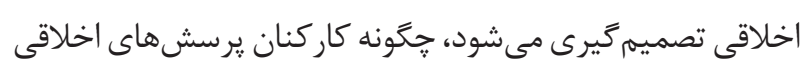

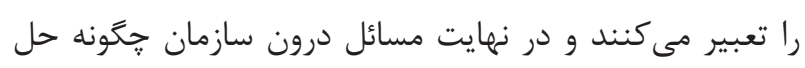

مى تردد (r) (r).

در بين نظريههاى اخلاقى مختلف، نظريه اخلاقى كالن (Cullen)

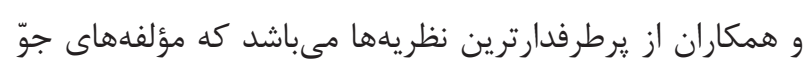

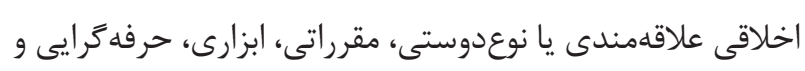

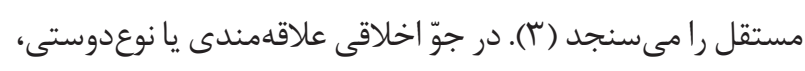

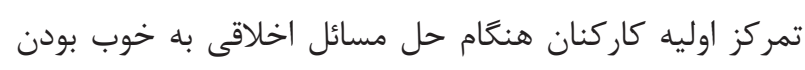

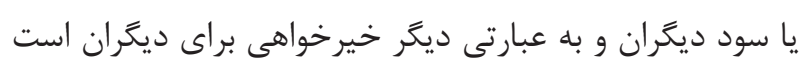

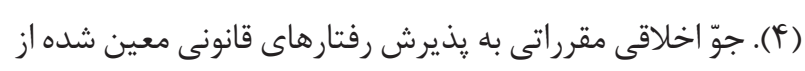

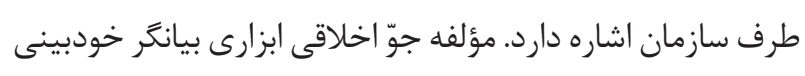

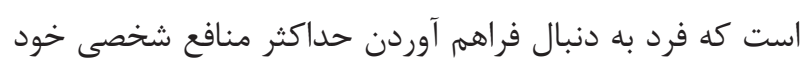

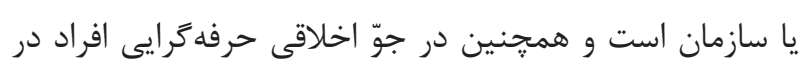

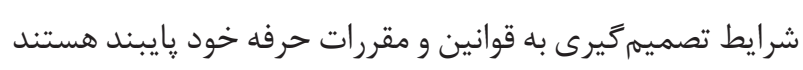

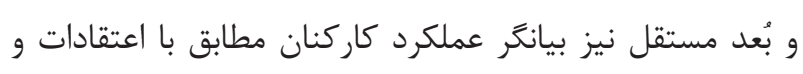

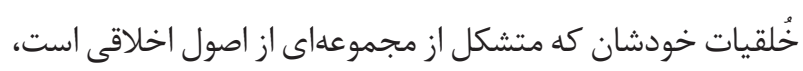
مىباشد (ه). از عوامل ديخر تأثير كذار بر سازمان تعهد سازمانى است و اين

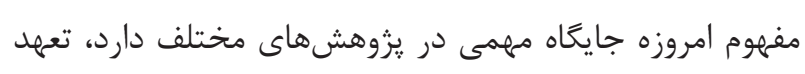

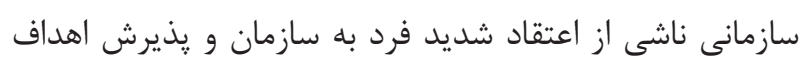

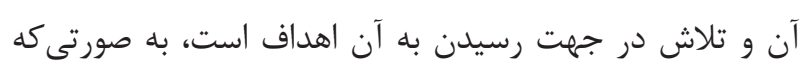

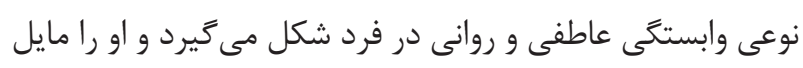

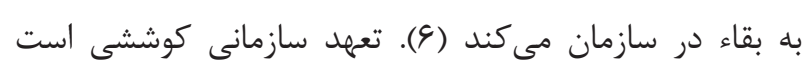
كه همه كاركنان از يايينترين تا بالاترين مرتبه مديريتى در دران مسير به دست آوردن اهداف و آرمانهاى سازمان انجام ميى دهند ماند (V) (V). از مهمترين عوامل وفادارى سازمانى الزام درونى برخاسته

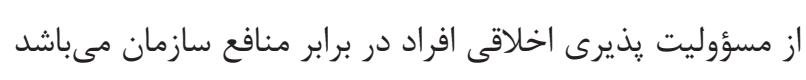

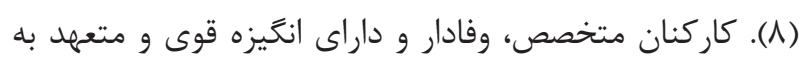

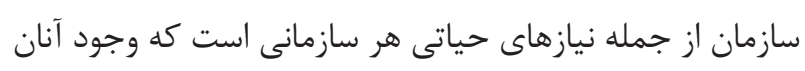
باعث كاهش غيبت، تأخير و جابه جايى، افزايش عملكرد سازمان و در نهايت محقق شدن اهداف متعالى سازمان خواهد شد (9). 
كاردانى، كارشناسى و يا كارشناسى ارشد اتاق عمل و مدرى

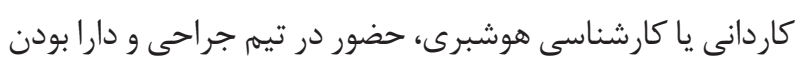

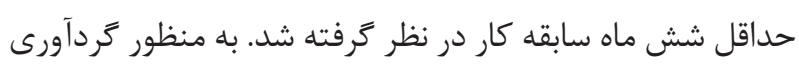

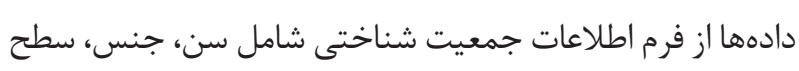

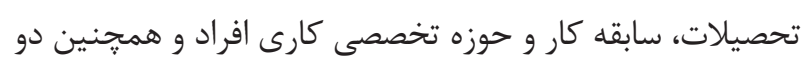

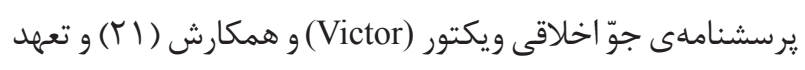

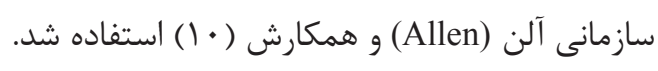

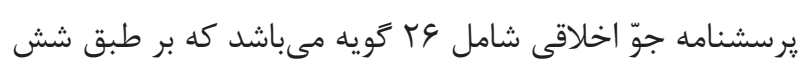

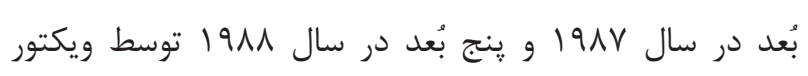

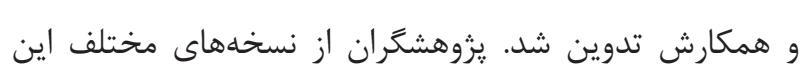

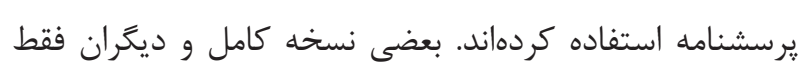

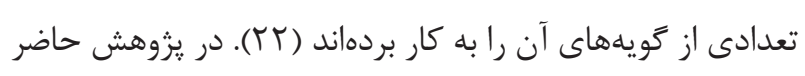

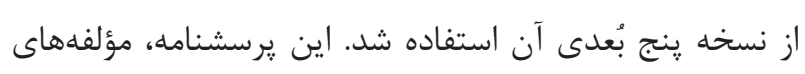

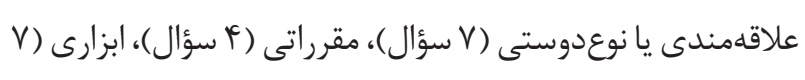

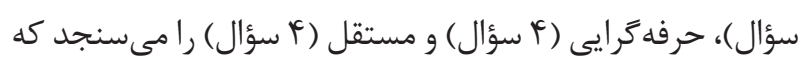

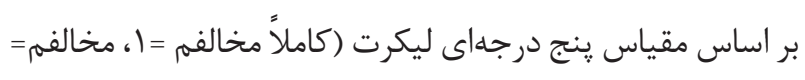

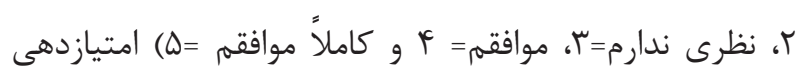
مىشود. بدين ترتيب، حداقل نمرهى كل ممكن براى هر مر فر فرد

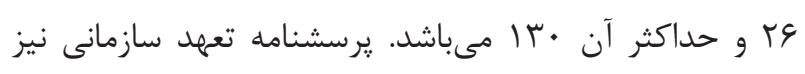

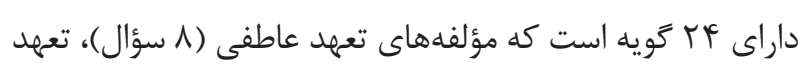
مستمر (1 سؤال) و تعهد هنجارى (1 سؤال) را ارزيابى مى كند. اين يرسشنامه داراى مقياس هفت درجهاى ليكرت (شامل كاملاً

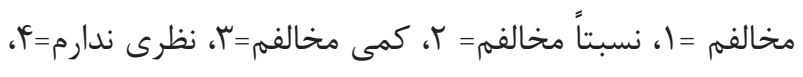

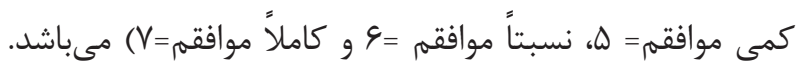

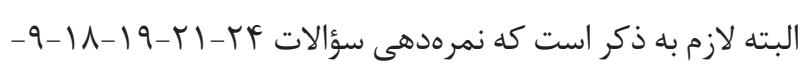
كا

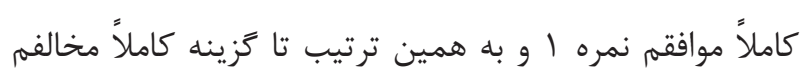

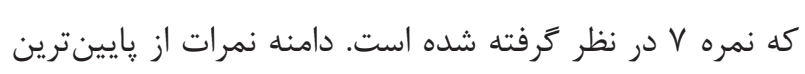

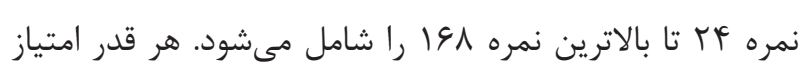

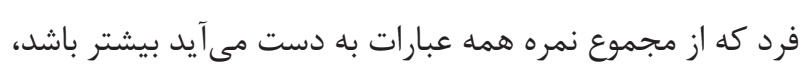
تعهد سازمانى او بالاتر است. به منظور مقايسه متغيرها، هر كدام بر مبناى · • إمحاسبه مىشود.

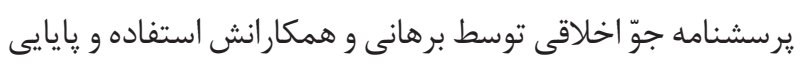

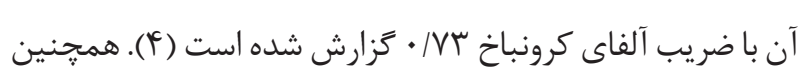

ارتباط مثبت و معنادارى بين جوّ اخلاقى از ديدكاه يرستاران

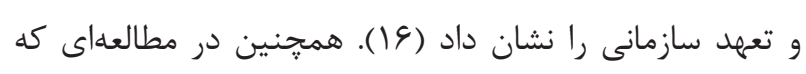

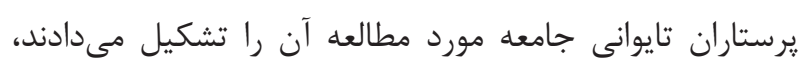

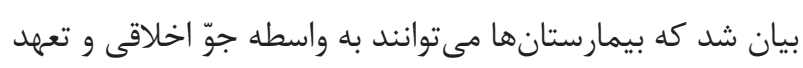

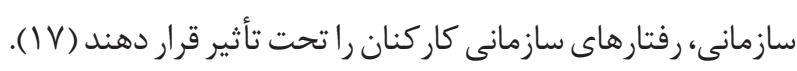
در ايران نيز مطالعات برهانى و همكاران بر ارتباط مستقيم ابعاد مختلف جوّ اخلاقى و تعهد سازمانى يرستاران تأكيد كردند (1) (1).

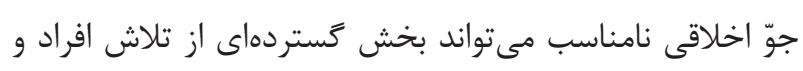

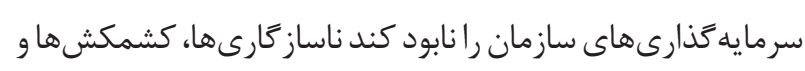
اختلاف نظرها از مشكلات بالقوهاى است كه در محيط با تعاملات بين فردى مانند اتاق عمل كه انجام وظايف تنگاتنگ آن توسط آنا

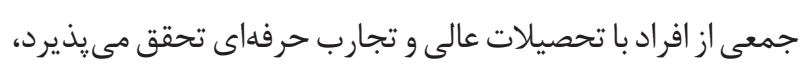

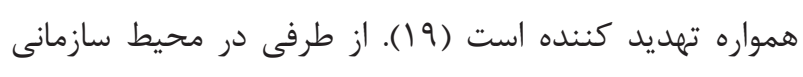

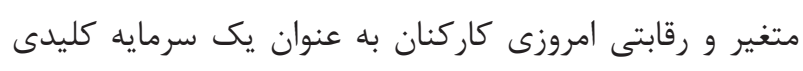

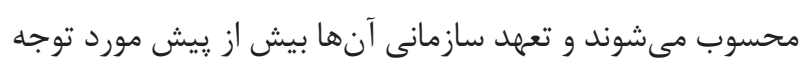
قرار مى گيرد (r· (r). يزوهشهاى صورت كَرفته يِيرامون جوّ اخلاقى بيمارستانى و

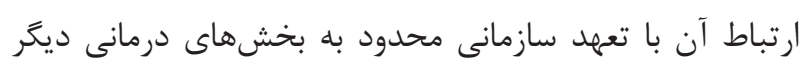

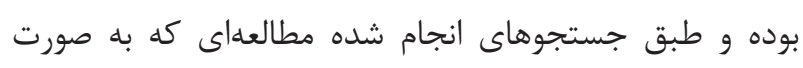

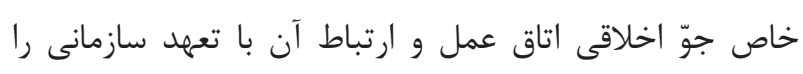

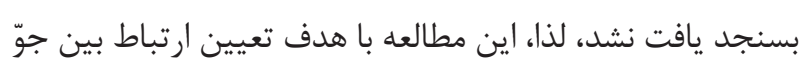

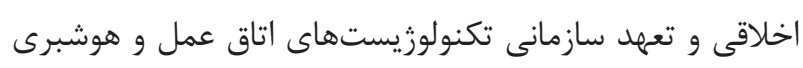

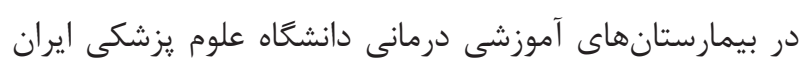

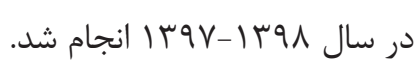

\section{مواد و روشها}

اين يزوهش يك مطالعه توصيفى تحليلى از نوع مقطعى است روته كه طى سالهاى 91

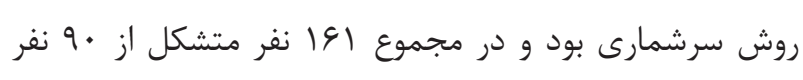

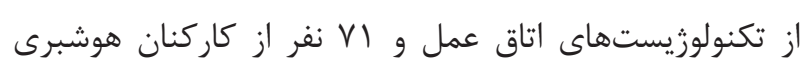

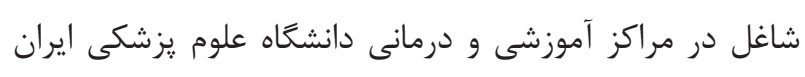

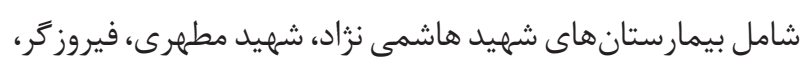

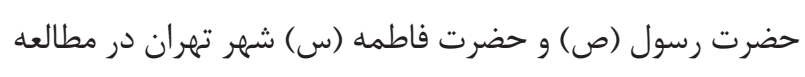

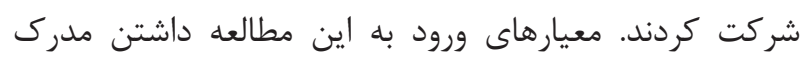


داشتند. ميانخين سنى افراد مورد مطالعه

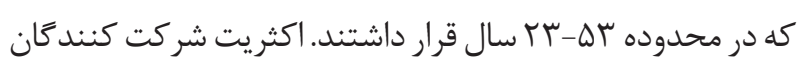

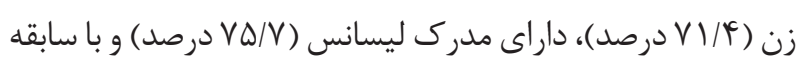

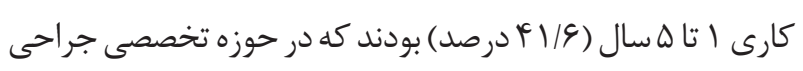

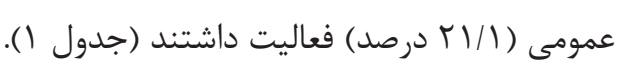

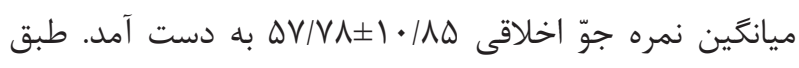

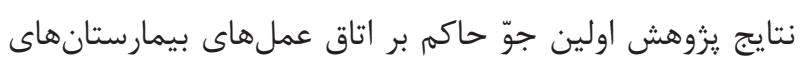

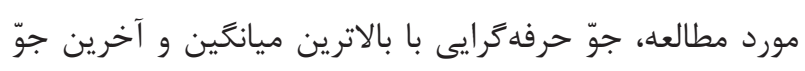

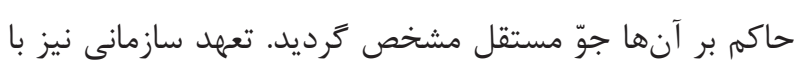

\begin{tabular}{|c|c|}
\hline فراوانى & مشخصات نمونه \\
\hline (درصد) & يزوهش \\
\hline
\end{tabular}

$110(V F)$

زن

\begin{tabular}{|c|c|c|}
\hline \&Q $(Y \wedge / \varphi)$ & مرد & \\
\hline $\mathrm{Vq}(19 / /)$ & • • تا •r سال & \multirow{4}{*}{ رده سنى } \\
\hline q (५ (५/।) & اس تا • F سال & \\
\hline $\operatorname{IV}(1 \cdot 19)$ & أFl تا • س سال & \\
\hline$r(1 / r)$ & بالاى •ه سال & \\
\hline ५q (TF/r) & فوق دييلم & \multirow{2}{*}{ تحصيلات } \\
\hline ITr (VD/V) & ليسانس & \\
\hline$G V(F / / G)$ & ا تا ه سال & \multirow{6}{*}{ سابقه كار در واحد } \\
\hline$r V(|\&| \Lambda)$ & ع تا • ا سال & \\
\hline$r \cdot(1 \wedge / \varepsilon)$ & 11 ا تا ه| سال & \\
\hline$F F(\mid F / q)$ & عا تا •r سال & \\
\hline $1 \cdot(9 / T)$ & آY تا ه سال & \\
\hline$r(1 / 9)$ & צץ تا •r سال & \\
\hline TF (YI/I) & جراحى عمومى & \multirow{8}{*}{ حوزه تخصصى } \\
\hline $1 f(\Lambda / V)$ & جراحى مغز و اعصاب & \\
\hline$r \mid(\mid r)$ & جراحى يوست و ترميمى & \\
\hline $9(\Delta / 9)$ & جراحى جشم & \\
\hline$r q(19 / 1)$ & جراحى ارولوزى & \\
\hline$r \mid(I r)$ & جراحى گوش، حلق و & \\
\hline$r q(1 \wedge)$ & جراحى ارتويدى & \\
\hline$V(\boldsymbol{Y} / \boldsymbol{\Gamma})$ & جراحى زنان & \\
\hline
\end{tabular}

يرسشنامه تعهد سازمانى توسط غياثونديان و همكاران مورد

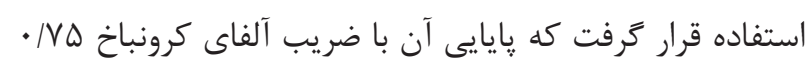

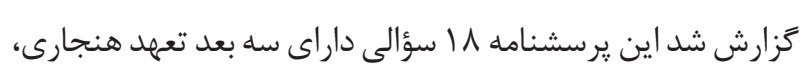

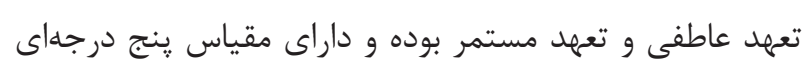

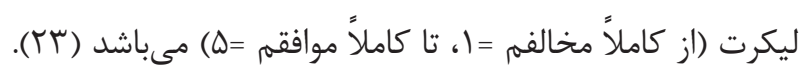

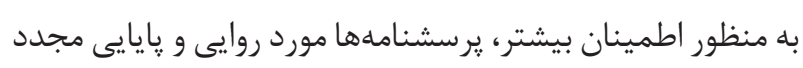

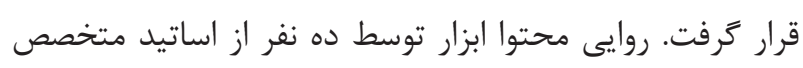

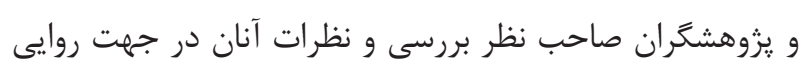

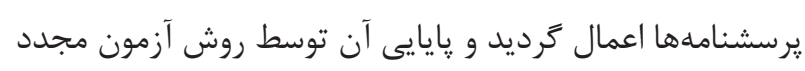

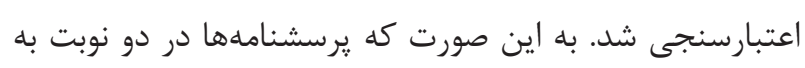

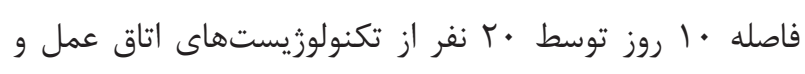

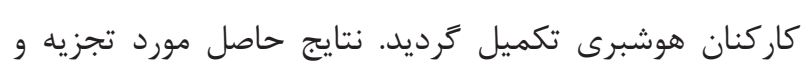

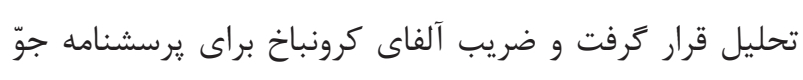

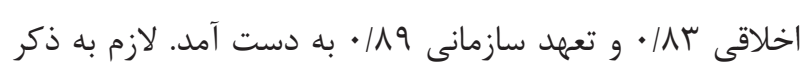

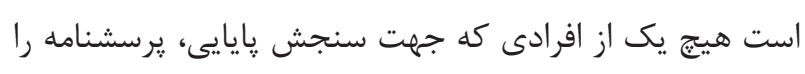
ير كردند به عنوان نمونه انتخاب نشدند.

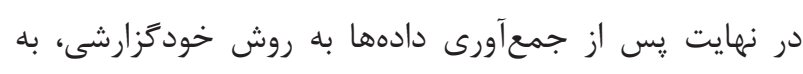

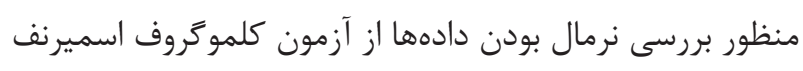

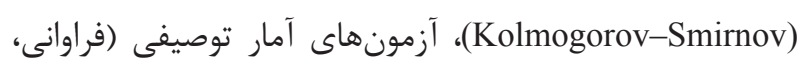

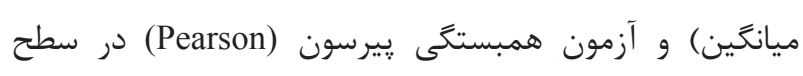

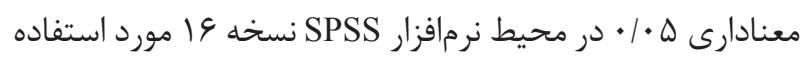

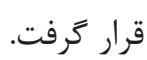

اين يزوهش در كميته اخلاق در يروهش دانشعاه علوم يزشكى ايران

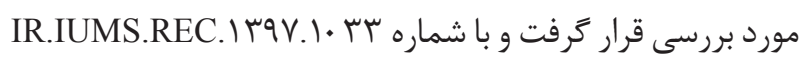

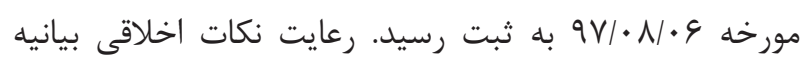

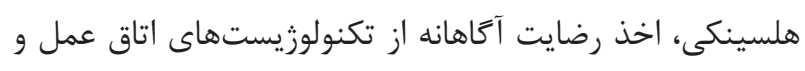

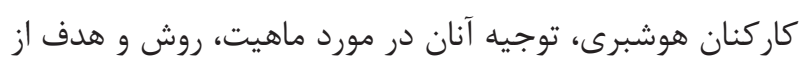

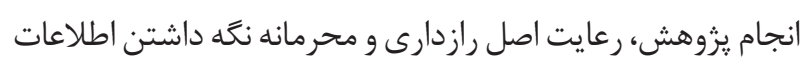

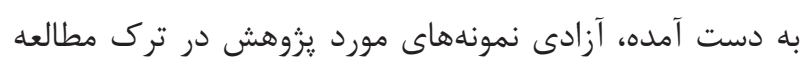

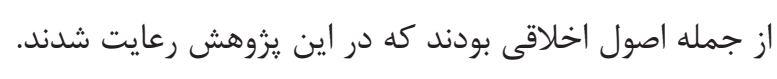

يافته ها در اين يزوهش |ع| نفر از يرسنل اتاق عمل و هوشبرى شاغل در

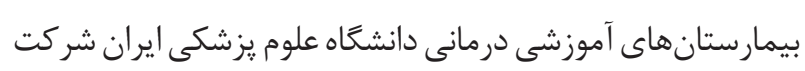




\section{بحث و نتيجه}

مطالعه حاضر با هدف تعيين ارتباط بين جوّ اخلاقى و تعهد ديرى

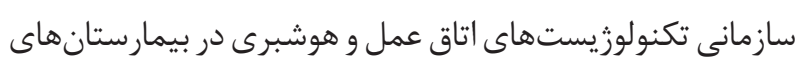

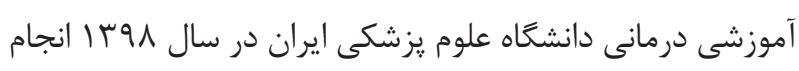

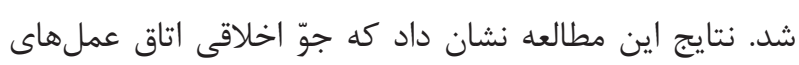

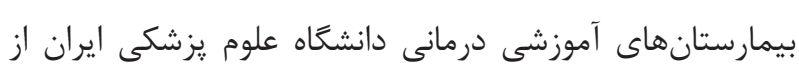

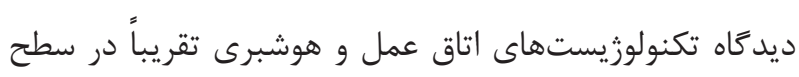

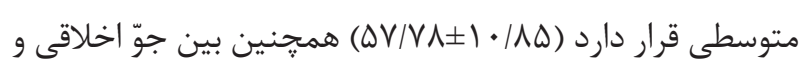

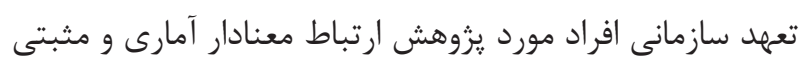

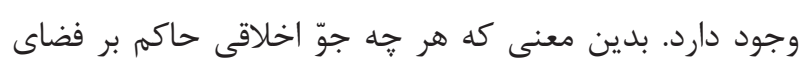

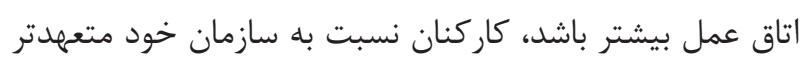

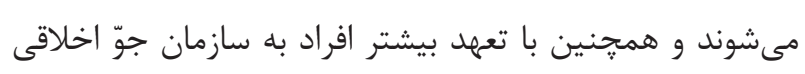

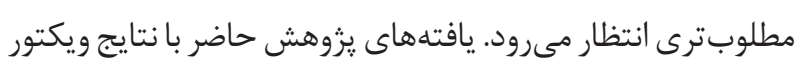
(Victor)

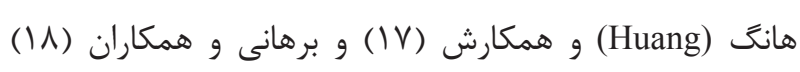

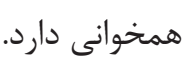
بالا بودن جوّ اخلاقى سازمان موجب افزايش حمايت سازئ سازمانى از

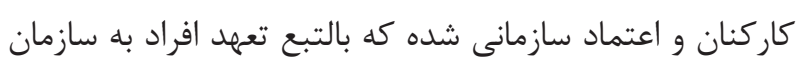

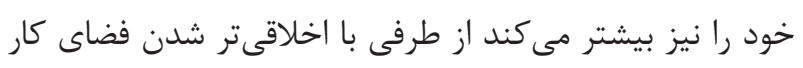

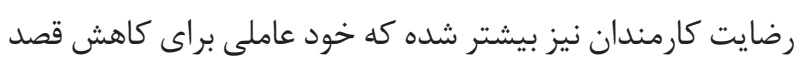
ترك خدمت و از دست رفتن منابع انسانى مىشود (TF).

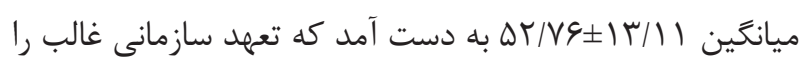

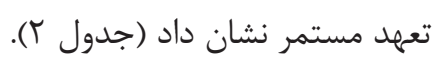
يافتههاى حاصل از نتايج آزمون كولموكروف - اسميرنف نشان نشان

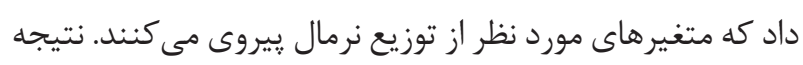

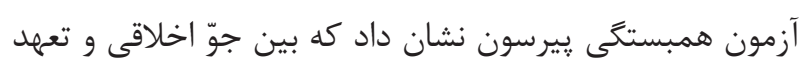

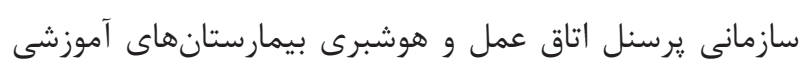

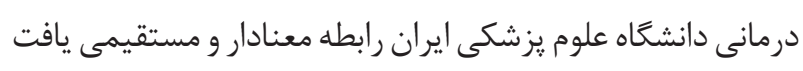

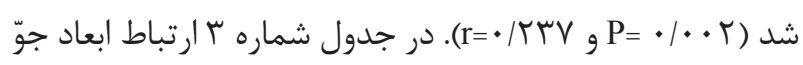
اخلاقى و تعهد سازمانى نشان داده شده است.

جدول r - ابعاد جوّ اخلاقى و تعهد سازمانى

\begin{tabular}{|c|c|c|}
\hline ميانگين و انحراف معيار & كويه & متغير \\
\hline$G / / \Delta \Delta \pm / \Delta / r \Lambda$ & جوّ اخلاقى نوعدوستى & \multirow{6}{*}{ جوّ اخلاقى } \\
\hline$G \Delta / q 1 \pm I V / r V$ & جوّ اخلاقى حرفهَرايى & \\
\hline $9 \Delta / \Delta r \pm 19 / 9 \Lambda$ & جوّ اخلاقى مقرراتى & \\
\hline$\Delta r / V \Delta \pm I F / T r$ & جوّ اخلاقى ابزارى & \\
\hline$F F / \mid r \pm 1 q / v q$ & جِّ اخلاقى مستقل & \\
\hline$\Delta \mathrm{V} / \mathrm{V} \wedge \pm 1 \cdot / \wedge \Delta$ & جوّ اخلاقى كل & \\
\hline$\Delta r / g r \pm \mid V / 19$ & تعهد عاطفى & \multirow{4}{*}{ تعهد سازمانى } \\
\hline$\Delta F / \Lambda \mid \pm 19 / V K$ & تعهد مستمر & \\
\hline$\Delta \cdot\left|\Lambda r_{ \pm}\right| r / r V$ & تعهد هنجارى & \\
\hline$\Delta r / V \varepsilon_{ \pm}|r / l|$ & تعهد سازمانى كل & \\
\hline
\end{tabular}

جدول بـ - ارتباط ابعاد جوّ اخلاقى و تعهد سازمانى واحدهاى مورد يزوهش

\begin{tabular}{|c|c|c|c|c|}
\hline تعهدد سازمانى كل & تعهد هنجارى & تعهد مستمر & تعهد عاطفى & متغير \\
\hline . MFF & .1199 & . & $* \cdot / \mu r$. & \multirow{2}{*}{ جوَ نوعدوستى } \\
\hline$\cdot 1 \cdot r$ & Th & $\cdot|T Y|$ & $<\cdot|\cdot|^{*}$ & \\
\hline DLA & $\cdot / 10 \cdot$ & $\cdot 11 \cdots$ & $\cdot r \cdot v$ & \multirow{2}{*}{ جوّ حرفهَرايى } \\
\hline$\cdot \cdot \cdot r$ & $\cdot 1 \cdot \Delta \Lambda$ & $\cdot / 7 \cdot 9$ & $<\cdot 1 \cdot \cdot 1$ & \\
\hline$\cdot / r \Delta F$ & מTf & $\cdot / 411$ & $\cdot /$ r & \multirow{2}{*}{ جوّ مقرراتى } \\
\hline$<\cdot 1 \cdot \cdot 1$ & $\cdot 1 \cdot r$ & $\cdot 1 \cdot \cdot V$ & $<\cdot 1 \cdot \cdot 1$ & \\
\hline$-\cdot / \cdot \wedge \Delta$ & $-\cdot \cdot \cdot V r$ & $\cdot|\cdot Y|$ & $-\cdot 1191$ & \multirow{2}{*}{ جوّ ابزارى } \\
\hline$\cdot / r \wedge F$ & $\cdot / T \Delta \Delta$ & ./Vqr & $\cdot|\cdot| 4 \mid$ & \\
\hline .1111 & .1 .94 & .1190 & $-\cdot 1 \cdot \cdot 1$ & \multirow{2}{*}{ جوّ مستقل } \\
\hline.$/ 195$ &.$/ T Y A$ & 1./. &.$/ 9 T F$ & \\
\hline (try &.$/ 109$ &.$/ 194$ &.$/ 4 r q$ & \multirow{2}{*}{ جوّ اخلاقى كل } \\
\hline$\cdot 1 \cdot r$ & $\cdot 1 \cdot p q$ & $\cdot 1 \cdot r V$ & r & \\
\hline
\end{tabular}


حمايت سازمانى كه كاركنان در اين نوع جو دريافت مىكنند

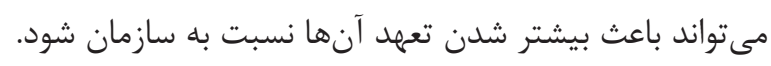

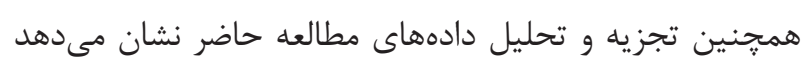

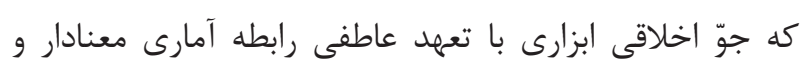

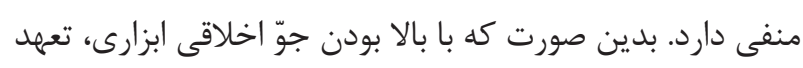

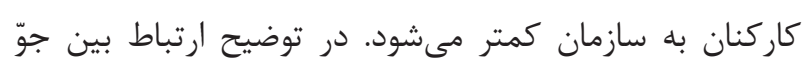

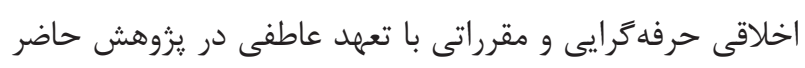

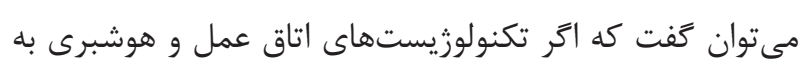

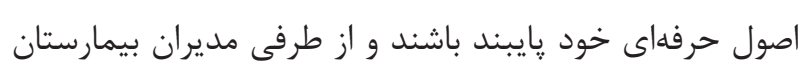

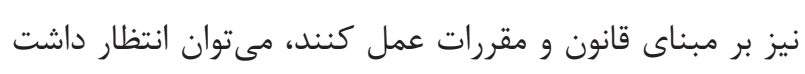

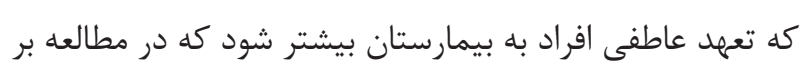

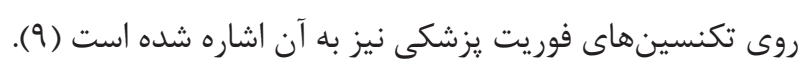

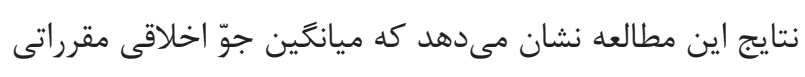
و جوّ اخلاقى حرفهرَايى بسيار به هم نزديك هستند و مىتوان

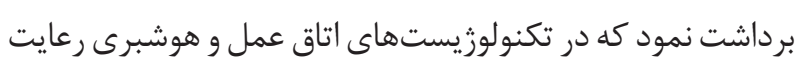
استانداردهاى حرفهاى در كنار قوانين و مقررات تعيين شده از

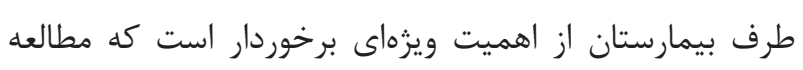
صورت گرفته روى برستاران نيز همخوانى دارد (1) (1).

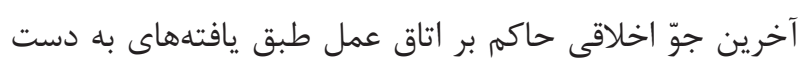

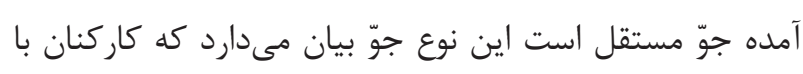

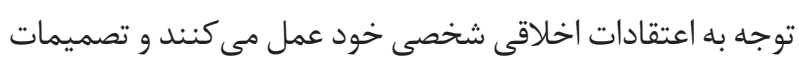

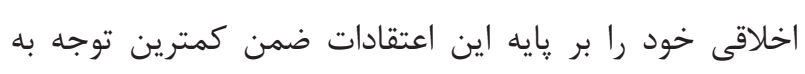
نيروهاى خارجى اتخاذ مى نمايند. جلالى و همكاران نيز جوّ مستقل

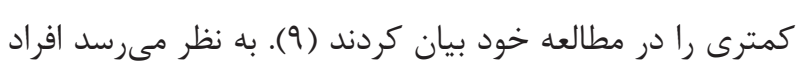
مورد يزوهش در اين مطالعه ضمن توجه به اصول حرفهاى خود

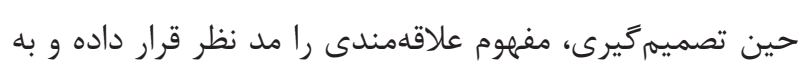

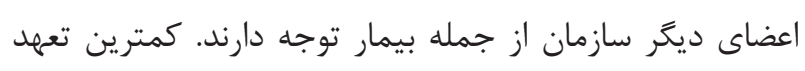

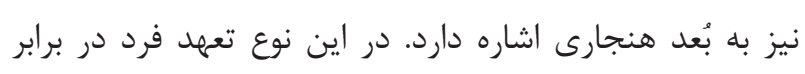

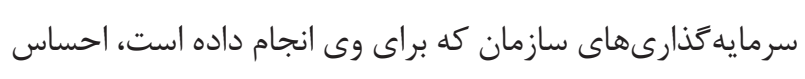

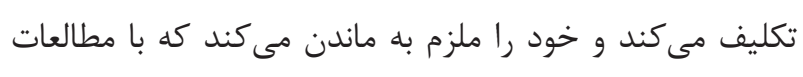

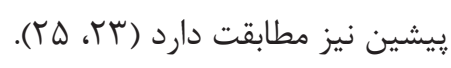
با توجه به نتايج يزوهش حاضر، جوّ اخلاقى و تعهد سازمانى

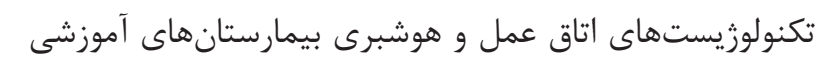
درمانى دانشكاه علوم يزشكى ايران در سطح متوسطى قرار عمل دارد.
با توجه به نتايج به دست آمده بالاترين درصد جوّ اخلاقى حاكم

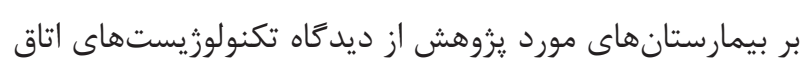

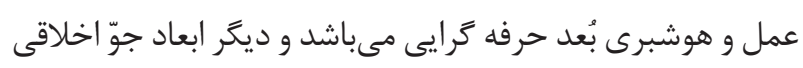

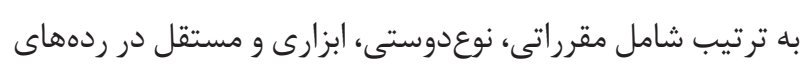

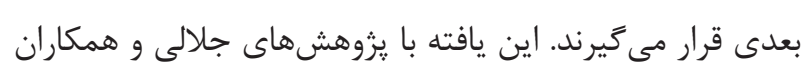

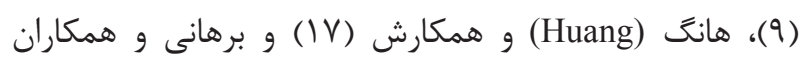

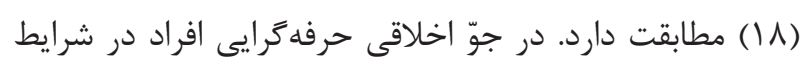

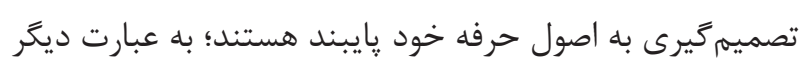

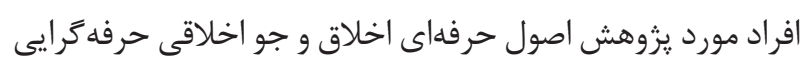

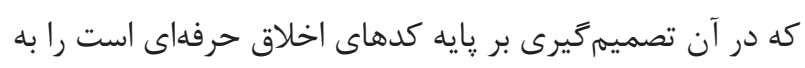

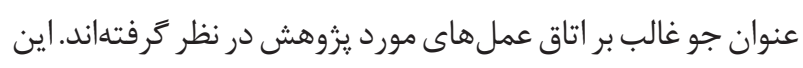
كدهاى اخلاق حرفهاى مجموعهاى از اصول و استانداردهايى است كه بايدها و نبايدهاى اخلاقى در هر حرفه را مشخص مى منى كند (1) (1). ميزان تعهد سازمانى افراد مورد يزوهش

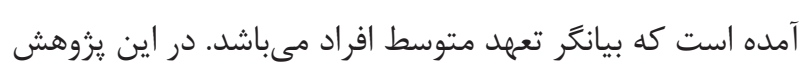

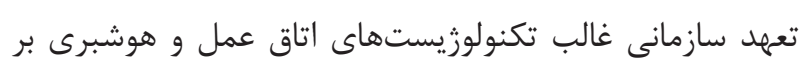
اساس تعهد مستمر است كه تمايل به باقى ماندن در سازمان

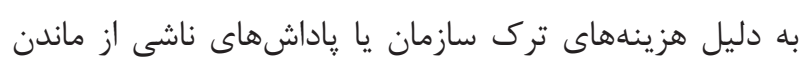
در سازمان را نشان مىدهد (9). اين يافته با نتايج غياثونديان

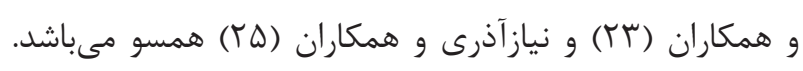

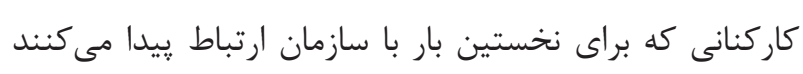

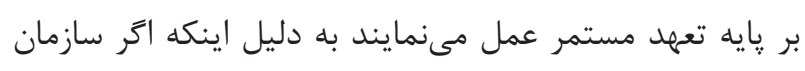

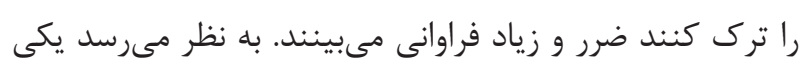
از دلايل وجود تعهد مستمر بين كاركنان اين است كه بيشترين

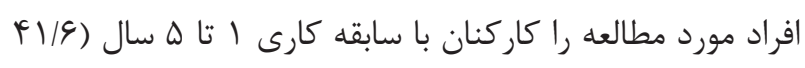
درصد) تشكيل دادهاند.

در اين يروهش شواهدى مبنى بر ارتباط ابعاد جوّ اخلاقى و تعهد داداند

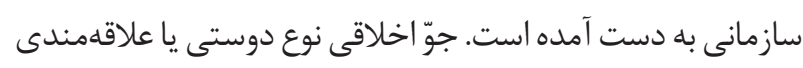

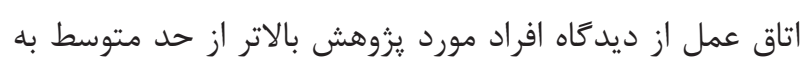
دست آمده است، بديهى است كه در جوّ نوعدوستى، افراد به إنه دلايلى نظير ارتباطات نزديك با يكديكر، تمايل و تعلق عاطفى به أنه

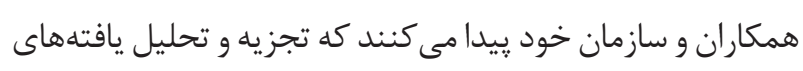

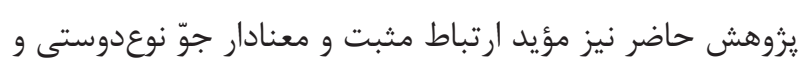
تعهد عاطفى در تكنولوزيستهاى اتاق عمل و هوشبرى مى باشد. 
و عقايد آنها تعهد سازمانى را به سمت تعهد عاطفى سوق داده كه كاركنان با ميل خود به سازمان احساس تعلق داشته بانه باشند.

\section{تشكر و قدردانى}

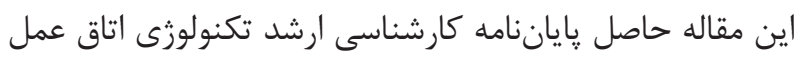

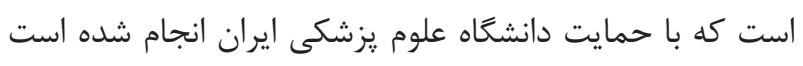
بدين وسيله نويسند

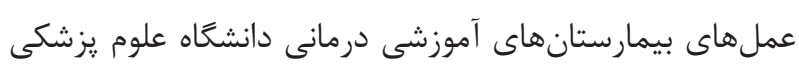

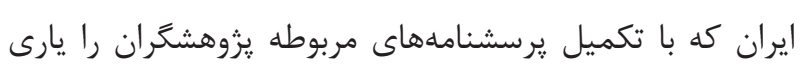

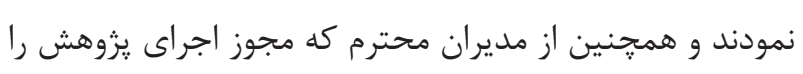
صادر كردند، صميمانه تشكر و قدردانى كنند.

تضاد منافع

بدين وسيله نويسند ان تصريح مى كنند كه هيج كونه تضاد منافعى در خصوص يزوهش حاضر وجود ندارد.

\section{References}

1- Borhani F, Jalali T, Abbaszadeh A, Haghdoost A. Viewpoint of Nurses about Ethical Climate of Educational Hospitals at Medical Science University of Kerman. Med Ethics J. 2011; 5(17): 18.

2- Jones G. Organizational theory, design, and change: Upper Saddle River. NJ: Pearson; 2013.

3- Borhani F, Hoseini H, Zadeh A, Abbasi M, Fazljoo E. Nurses' perceptions of ethical climate governing the teaching hospital affiliated with the University of Medical Sciences Shahid Sadughi Yazd. Med Ethics J. 2015;8(29):41-65.

4- Cullen J, Parboteeah K, Victor B. The effects of ethical climates on organizational commitment: A two-study analysis. J Business Ethics. 2003;46(2):127-41. DOI: 10.1023/a:1025089819456

5- Borhani F, Atashzadeh Shoorideh F, Amin Pour Hossein Gholi M, Maani S. The Correlation between Ethical Climate and Job Satisfaction of the Nurses in Shahid Beheshti University of Medical Sciences. Med Ethics J. 2017;10(38):51-8. DOI: 10.21859/mej-103851

6- Boyokzadeh F, Navipour H, Vanaki Z, Asareh M. Reflection of emotional intelligence's nurse managers on nurses' organizational commitment. Quarterly J Ners Manage. 2017; 6(1): 42-52. DOI: 10.29252/ijnv.6.1.42

7- Engin E, Akgöz B. The effect of communication satisfaction on organizational commitment. BJASS. 2013; 14(2): 109-24.

8- Shadoloei L, Torani H. Management of practical ethics in educational organizations. Growth School Manage. 2011(4): 2832.
همجنين با توجه به وجود ارتباط مستقيم بين جوّ اخلاقى و تعهد

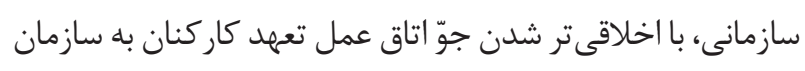
نيز بيشتر مىشود.

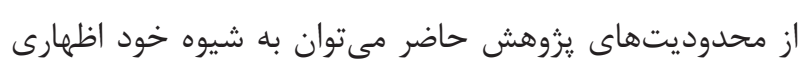

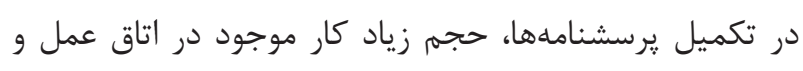

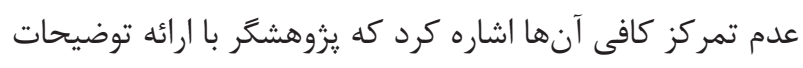

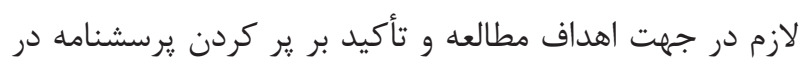

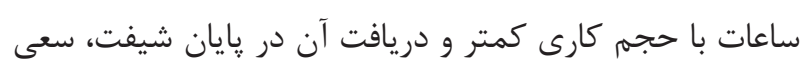

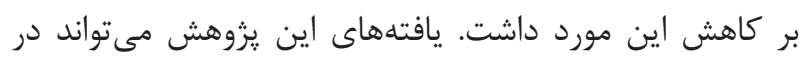

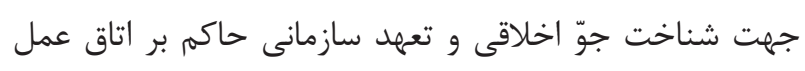
و برنامهريزى به منظور بهبود و ثبات آن، به مديران بيمارستانى

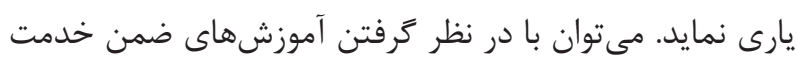

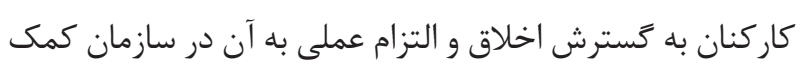

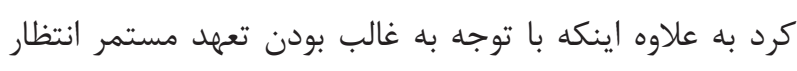

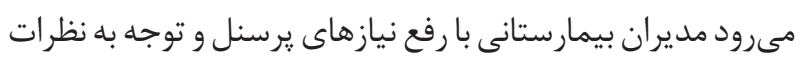

9- Jalali T, Borhani F, Esmailpur H, Aliesmaeli M, Aminizade M, Motamed jahromi M. Relationship Between ethical climate and Organizational Commitment of Medical Emergency Technicians in Kerman University of Medical Sciences. J Med Ethics \& History Med. 2017; 10(1): 91-102.

10- Meyer J, Allen N. A three-component conceptualization of organizational commitment. Human Resource Manage Review. 1991;1(1):61-89. DOI: 10.1016/1053-4822(91)90011-z

11- Olson L. Hospital Nurses' Perceptions of the Ethical Climate of Their Work Setting. Image: the Journal of Nursing Scholarship. 1998;30(4):345-9. DOI: 10.1111/j.1547-5069.1998.tb01331.x PMID: 9866295

12- Schluter J, Winch S, Holzhauser K, Henderson A. Nurses' Moral Sensitivity and Hospital Ethical Climate: a Literature Review. Nursing Ethics. 2008;15(3):304-21. DOI: 10.1177/0969733007088357 PMID: 18388166

13- Hassani M, Sedaqat R, Kazemzadehbeytali M. Correlation between the Ethical climate, Job stress and Job Satisfaction in Nurses. Med Ethics J. 2017;11(40):63-71. DOI: 10.21859/mej114063

14- Schroeter K. Ethical Perception and Resulting Action in Perioperative Nurses. AORN Journal. 1999;69(5):991-1002. DOI: 10.1016/s0001-2092(06)62297-7

15- Killen A. Morality in Perioperative Nurses. AORN Journal. 2002;75(3):532-49. DOI: 10.1016/s0001-2092(06)61175-7

16- Abou Hashish E. Relationship between ethical work climate and 
nurses' perception of organizational support, commitment, job satisfaction and turnover intent. Nursing Ethics. 2015; 24(2): 15166. DOI: 10.1177/0969733015594667 PMID: 26260440

17- Huang C, You C, Tsai M. A multidimensional analysis of ethical climate, job satisfaction, organizational commitment, and organizational citizenship behaviors. Nursing Ethics. 2012; 19(4): 513-29. DOI: 10.1177/0969733011433923 PMID: 22753457

18- Borhani F, Jalali T, Abbaszadeh A, Haghdoost A. Nurses' perception of ethical climate and organizational commitment. Nursing Ethics. 2013;21(3):278-88. DOI: 10.1177/0969733013493215 PMID: 24019306

19- Fazel E, Abbassioun K, Sehhat S, Jaberansari M, Akashe G, Hesabi A, et al. Operating Room The Base Of Morality And The Basis Of Humanistic Professional Duties. Iranian J Surg. 2017(25):131-87.

20- Salehi M, Dadgar Z. The relationship between professional ethics and organizational Commitment From the viewpoint of nurses in Imam Khomeini hospital in Sari. Bioethics Journal. 2016; 6(20): 14.
21- Victor B, Cullen J. The Organizational Bases of Ethical Work Climates. Administrative Science Quarterly. 1988; 33(1): 101. DOI: $10.2307 / 2392857$

22- Kincaid C. An examination of the effect of ethical climate on ethical optimism and organizational commitment. USA: Nevada; 2003.

23- Ghiyasvandian S, Sedighiyani A, Kazemnejad A, Iranshahi I. Relationship between organizational communication satisfaction and organizational commitment in nurses. J Med Ethics \& History Med. 2017; 9(6): 20-33.

24- Koskenvuori J, Numminen O, Suhonen R. Ethical climate in nursing environment: A scoping review. Nursing Ethics. 2017; 26(2): 327-45. DOI: 10.1177/0969733017712081 PMID: 28659068

25- Niazazari K, Enayati T, Behnamfar R, Kahroodi Z. Relationship between Professional Ethics and Job Commitment. Iran J Nurs. 2014; 27(87): 34-42. DOI: 10.29252/ijn.27.87.34 